\title{
TRADUZINDO THE AWFUL ROWING TOWARD GOD, DE ANNE SEXTON, PARA O PORTUGUÊS BRASILEIRO ATRAVÉS DA PERSPECTIVA DOS ESTUDOS FEMINISTAS DE TRADUÇÃO
}

${ }^{1}$ Universidade Federal de Santa Catarina, Santa Catarina, Florianópolis, Brasil

\begin{abstract}
Resumo
Este trabalho ${ }^{1}$ busca compartilhar resultados de minha tradução para o português brasileiro, a partir do enfoque dos Estudos Feministas de Tradução do livro The Awful Rowing Toward God (1975), escrito por Anne Sexton, Ao realizar a tradução comentada desse livro, parte de minhas reflexões teóricas se deu através desse campo de pesquisa, que demonstra o quanto o gênero gramatical pode refletir hierarquias de gênero sexual e, portanto, é um tópico de debate e crítica feminista. Tal problemática é muito relevante ao considerar pares de línguas como o inglês e o português, pois o primeiro não possui marcação de gênero gramatical, exceto para pronomes e alguns substantivos, e o segundo o tem. Uma vez que Anne Sexton é valorizada tanto pela crítica literária feminista quanto por outras autoras feministas, reconheço como necessário que sua tradução seja feita com uma consciência de gênero em prol de uma tradução não sexista.

Palavras-chave: The Awful Rowing Toward God; Anne Sexton; Tradução; Estudos Feministas de Tradução; Tradução não sexista.
\end{abstract}

\section{TRANSLATING ANNE SEXTON'S THE AWFUL ROWING TOWARD GOD TO BRAZILIAN PORTUGUESE THROUGH THE FEMINIST TRANSLATION STUDIES' PERSPECTIVE \\ Abstract}

This paper aims to share results of my translation to Brazilian Portuguese, through the Feminist Translation Studies approach of the book The Awful Rowing Toward God (1975), written by Anne Sexton,. When I did the commented translation of this book, part of my theoretical reflections went through this field of research, which demonstrates how grammatical gender can reflect hierarchies of sexual gender and, therefore, it is a topic of feminist debate and criticism. This sort of problematic is very relevant regarding language pairs such as English and Portuguese, for the first one does not have grammatical gender marking, except for pronouns and

\footnotetext{
* Doutoranda em Estudos da Tradução na Universidade Federal de Santa Catarina, com apoio de bolsa CAPES. Mestra em Estudos da Tradução pela Universidade Federal de Santa Catarina (2018). Faz parte do Grupo de Estudos Feministas na Literatura e na Tradução (GEFLIT) na Universidade Federal de Santa Catarina. É tradutora, revisora, editora e escritora. Seu e-mail é: beatriz.r.guimaraes@gmail.com. ORCID ID: 0000-00028045-4912
} 
some nouns, and the second one has. As Anne Sexton is valued by the feminist literary criticism and by other feminist authors, I recognize that it is necessary that the translation of Anne Sexton's book ought to be done with a consciousness of gender for a non-sexist translation.

Keywords: The Awful Rowing Toward God; Anne Sexton; Translation; Feminist Translation Studies; Non-sexist translation. 


\section{Introdução}

Para que o título deste trabalho se tornasse o que agora se mostra, foi preciso uma análise crítica retrospectiva de seu percurso, sendo seu objeto o último livro de poemas escrito e revisado por Anne Sexton antes de seu suicídio em 1974. A primeira vez em que apresentei essas reflexões foi na conferência Translation \& Minority 2, realizada pela Escola de Tradução e Interpretação da Universidade de Ottawa, em 2017, então com o título de "Translating Anne Sexton to Brazilian Portuguese: regarding questions of gender”. A comunicação se baseava em parte de minha dissertação em andamento na época, uma tradução comentada do livro The Awful Rowing Toward God (SEXTON, 1975), finalizada em julho de 2018. Menciono a apresentação para criticar seu próprio título e palavras-chave do resumo: ainda que meus referenciais fossem dos Estudos Feministas de Tradução, apenas os cito enquanto tais no resumo, em letras minúsculas (TRANSLATION \& MINORITY, online). Embora as palavras "gênero" (presente no título e nas palavras-chave), "feminismo" e "poesia de mulheres" (nas palavras-chave), conjuntamente a "tradução", façam parte do repertório do campo, elas não são suficientes para permitir uma conexão específica com os desenvolvimentos dele. Essa escolha, ainda que não totalmente consciente de suas implicações quando a tomei, reflete uma tendência acadêmica, conforme notado por José Santaemilia ao realizar uma análise de terminologia nos títulos de um corpus de 493 pesquisas na intersecção entre sexo/gênero, mulheres, feminismo e tradução:

While there has been a steady, though modest, increase in the use of feminist, the presence of gender has multiplied significantly. One of the possible reasons for this fact that feminism is often understood as focusing exclusively on women's equality and is also heavily stigmatised due to intense cultural backlash, while gender appears as a more neutral term. I contend that gender is seen as a broader, less threatening and less controversial concept that does not single out a specific group of people. (SANTAEMILIA, 2017, p. 21)

O problema de optar pela via que o conceito de gênero oferece é a diluição dos temas abordados por ele, flutuando em um grande conjunto que analisa questões de gênero sem necessariamente afirmar uma postura política contra desigualdades sociais. No entanto, muitas pesquisas sob o guarda-chuva do gênero abarcam de fato pautas feministas e conversam com os referenciais teóricos dos feminismos. No caso específico dos Estudos da Tradução (ET), a não utilização de uma terminologia comum, como Estudos Feministas de Tradução, dificulta localizar pesquisas nesse campo, o que pode impedir ou atrapalhar o diálogo nacional e transnacional entre trabalhos situados na intersecção entre tradução e gênero.

Ainda que tenha evitado tomar esse posicionamento em uma primeira circunstância, foi possível afirmar minha postura enquanto tradutora feminista com o desenvolvimento de minha dissertação. Fundamentando minhas reflexões 
nos Estudos Feministas de Tradução, encontrei aporte principalmente nos textos de Olga Castro, Luise von Flotow e também de Mona Baker, pesquisadora que, embora atue nos ET em sua dimensão mais ampla (por exemplo, como organizadora da Routledge Encyclopedia of Translation Studies, junto de Gabriela Saldanha), possui livros e artigos usados por teóricas/os feministas e críticas/os pós-coloniais devido à sua perspectiva política da atividade tradutória e teoria narrativa (CASTRO e ERGUN, 2016; BASSI, 2016; BOOTH, 2017; SHREAD, 2011). Uma das pontes para incluir essa perspectiva em um projeto de tradução comentada, para além de afinidades pessoais, deu-se pela leitura do texto "Anne Sexton: 1928-1974", escrito por Adrienne Rich (1995). O ensaio reverbera opiniões populares nos anos 70, nas quais autoras como Sylvia Plath e Anne Sexton figuravam como feministas (GREENE et al., 2012, p. 482), pois Rich valoriza os poemas de Sexton no debate de pontos nevrálgicos à representação de mulheres e homens escrita por mulheres.

É preciso dizer que aqui exponho um recorte de várias abordagens que se entrelaçaram no processo de tradução de The Awful Rowing Toward God. O livro tem diversos outros aspectos fundamentais que foram trabalhados em minha dissertação, brevemente comentados em um artigo sobre o poema "The Wall" (BARBOZA, 2017). Um de seus elementos que mais se destaca é o teor espiritual, manifestado em aspectos tanto de conteúdo quanto formais, por exemplo, em: 1) a estrutura composta pelo conjunto dos poemas, que apresenta uma narrativa de conversão moderna no formato da Preparationist Theology (MORTON, 1989); 2) sua dinâmica interna que se vale de tópicos religiosos e das figuras de Deus, Maria e Jesus para adentrar em temas psicanalíticos (NICHOLS, 1988); 3) a temática recorrente da interconexão espiritual entre os seres e a divindade, dialogando com a tradição do misticismo erótico "ocidental" (SCHURR, 1988); 4) a utilização de vocabulário bíblico, citações de passagens da Bíblia e referências à sua imagética (SEXTON, 1975). É pertinente destacar que os pontos 2 e 3 são atravessados por questões de gênero: o primeiro destes por desenvolver o tema de retorno ao útero ao buscar a unificação da persona poética com a figura da mãe, simbolizada pelo mar, presente no livro; o segundo destes por haver grande presença de escritos de mulheres na tradição do misticismo erótico “ocidental" (Teresa D’Ávila, Hadewijch da Antuérpia, Mechthild de Magdeburgo, por exemplo). Porém, limito-me somente à percepção desses aspectos, uma vez que não é meu objetivo entrar em uma discussão aprofundada sobre gênero na mística e na psicanálise através de um objeto literário, mas para indicar mais portas de entrada ao debate feminista na poesia de Anne Sexton. Outra dimensão, trabalhada em minha dissertação, mas deixada de lado neste artigo por questões de espaço, são as reflexões sobre a poética em inglês, conforme Philip Hobsbaum e Derek Attridge, e as formas de traduzir poesia ao português brasileiro, inspiradas por Ana Cristina Cesar, Álvaro Faleiros e Paulo Henriques Britto.

Neste artigo, portanto, buscarei primeiro levantar os principais argumentos de Adrienne Rich ao reconhecimento da poesia e vida de Sexton como relevante às reflexões feministas, pensando em minha tradução do livro The Awful Rowing 
Toward God, que traduzi como O Terrível Remar Rumo a Deus. Com essa abertura para pensar o processo dentro dos Estudos Feministas de Tradução, contextualizálos-ei brevemente para explicar quais parâmetros orientaram minha perspectiva tradutória. Em especial, com a proposta de tradução não sexista entre o par de língua inglês-português, uma vez que a primeira não possui gênero gramatical e, a segunda, sim. Então, comentarei sobre alguns casos do livro de Anne Sexton para demonstrar como negociei com as questões de gênero e as demandas de tradução poética, concluindo com um breve reconhecimento do auxílio que os Estudos Feministas de Tradução forneceram à minha pesquisa.

\section{Uma leitura sobre Anne Sexton e sua poesia através de Adrienne Rich}

O suicídio de Anne Sexton em 1974, 11 anos depois de Sylvia Plath ter se matado, é um tópico até hoje muito debatido. Frequentemente é discutido em tom apelativo ou romantizado, devido à repercussão da biografia de Anne Sexton feita por Diane Middlebrook (1992), escrita com acesso a 300 horas de terapia da poeta, chamada de "patografia" por Joyce Carol Oates (POLLIT, 1991, online). A frequência desse fenômeno suicida entre mulheres foi observada durante o período de desenvolvimento de minha pesquisa, pois, na época em que escrevia sobre este assunto, recebi através do jornal The Guardian a notícia do suicídio da autora Jean Stein. Além disso, um mês antes desse acontecimento, foi lançado 13 Reasons Why, série televisiva na qual a protagonista se mata, sendo este seu motivo central. Esse aspecto autodestrutivo, para além de sua ocorrência no meio literário e artístico, tem sido objeto de estudo, como se pode ver nas análises de Simone de Beauvoir sobre o masoquismo em mulheres como uma das derivações destas apreenderem-se a si como objetos e não como sujeitos, agindo contra o próprio corpo ao invés de se realizarem em ações no mundo (BEAUVOIR, 2016[1949]). Porém, dessas leituras ressalto o clamor feminista pela vida das mulheres, como Adrienne Rich formulou em seu ensaio escrito pouco após Anne Sexton ter se matado: "We have had enough suicidal women poets, enough suicidal women, enough self-destructiveness as the sole form of violence permitted to women" (1995, p. 122). De fato, o último ato de Anne Sexton, por si só, revela uma lamentável realidade na qual mulheres ao redor do mundo, por diversas razões, não conseguem lutar contra as estruturas sociais, psicológicas, econômicas e de outras ordens que as oprimem. Assim, a morte de Anne Sexton é representativa da urgência das pautas feministas.

Muito além disso, porém, encontra-se sua própria poesia. Com a força de sua vida, Sexton teve a audácia e persistência de delinear e aprofundar-se em temas importantes à representação literária de mulheres e de homens por autoras e mulheres poetas. Conforme afirma Rich:

Anne Sexton was a poet and a suicide. She was not in any conscious or self-defined sense a feminist, but she did some things ahead of the rebirth of the feminist movement. She wrote poems alluding to abortion, 
masturbation, menopause, and the painful love of a powerless mother for her daughters, long before such themes became validated by a collective consciousness of women, and while writing and publishing under the scrutiny of the male literary establishment. (1995, p. 121)

Sintonizando com as pautas da chamada segunda onda do feminismo "ocidental" que giravam em torno da libertação sexual das mulheres, seus poemas exploravam tópicos sexuais e afetivos bem antes de serem amplamente debatidos, sendo até hoje uma das questões relevantes à literatura escrita por mulheres. Esse aspecto atravessa sua obra, incluindo The Awful Rowing Toward God, ainda que nesse livro prevaleça a relevância da representação multifacetada de uma persona poética que se inscreve no feminino, em sua busca e tentativa de diálogo com a Divindade através de si, da natureza e da sociedade. Logo no primeiro poema, "Rowing", Sexton escreve sobre uma persona poética que se depara com limitações e opressões desde a infância escolar,

little rows of chairs,

blotting my name over and over,

but undersea all the time,

a stranger whose elbows wouldn't work

(SEXTON, 1975, p. 1)

até a vida adulta, árdua e fria com suas "cruel houses", "people who seldom touch -/ though touch is all" e com "saws working through my heart" $(1975$, p. 1). No próximo poema, "The Civil War", o conflito interno ganha a dimensão de uma guerra civil - sugerindo, por um lado, uma dimensão extrema e, por outro, que essa cisão interna psicológica também pode ser de ordem social. Separada de si, agredida pela realidade, a persona poética almeja por uma unificação psíquica, emocional, espiritual e até física, e vislumbra-a em Deus, afirmando "but I will conquer them all [os pedaços quebrados de Deus em si]/ and build a whole nation of God/ in me - but united" (1975, p. 3). Se o tema pode referir-se a uma crise pessoal que busca se resolver pela fé, os motivos de sua fragmentação psicológica não deixam de ser marcados por questões de gênero, como mais à frente aparece no poema "The Play":

I am the only actor.

It is difficult for one woman

to act out a whole play.

The play is my life,

my solo act.

$(1975$, p. 38)

Ainda que a primeira pessoa da poesia confessional induza à conexão entre o gênero de quem escreve e a voz nos poemas - muito erroneamente, com frequência, ao perder de vista o aspecto performático dessa tradição, em que poetas realizam uma reescrita ficcional de si (GILL, 2007) -, é no poema "The Witch's Life" que se pode inferir que a voz é a de uma mulher. Isso é percebido não 
através de si, mas por aquela que pensa estar se tornando: "I think of her [A Bruxa] sometimes now/ and wonder if I am becoming her" (SEXTON, 1975, p. 11). Assim, o percurso do livro é a narração de uma mulher sobre seus questionamentos a respeito de Deus e suas criações (a Humanidade e a Natureza), sendo que essa compreensão (pela via cognitiva) e conexão (pela via afetiva) é interditada quase até o fim do livro pela própria condição da persona poética. Essa estaria marcada pelo mal, localizado pela persona como um animal dentro de si, que figura no primeiro poema como um rato a ser abraçado por Deus (a inferioridade em si acolhida pela Divindade), e adiante como um caranguejo, em alusão a um câncer, que talvez seja sua ignorância de Deus ("The Poet of Ignorance”, 1975, p. 29-30). Atravessando momentos de esperança e outros de desamparo, esboça a existência de um mal que se apossa dos seres humanos, a despeito de sua vontade, e não pode ser extirpado, embora ela o deseje - a persona busca a Divina Graça como salvação ao longo do livro. Essa procura, entende-se, deriva de não reconhecer Deus em si, como se vê em "The Sickness Unto Death" - "God went out of me" (1975, p. 40) - e em "Is It True?" - "Maybe my mother cut the God out of me" (1975, p. 50), nomeando-se de Ms. Dog (palíndromo de God). Aqui, as relações entre a persona e o mal através de uma imagem animal em si, e entre a ausência de Deus como culpa da intervenção da mãe, reverberam nos debates de gênero: a primeira por inserir-se nas dicotomias historicamente construídas entre NaturezaMulher-Sentimento e Cultura-Homem-Razão; a segunda como o afastamento de Deus (o Logos) através de uma figura feminina, a ancestralidade de mulheres representada pela mãe. No livro, então, a persona poética recorre a médicos para tentar arrancar o animal/mal de dentro de si em "The Poet of Ignorance" (1975, p. 28-29) e recebe aconselhamentos de padres a respeito em "The Sickness Unto Death" (1975, p. 40-41) e “Is It True?" (1975, p. 49-50). Adiante, a persona busca ajuda com seu marido para seus questionamentos niilistas, em versos que denotam dependência "and went in search, it could be said,/ of my husband (i.e. the one who carries you through)" (1975, p. 62, meu itálico). Importante notar que, ao comentar sobre o fato de o brilho da vida social, para as mulheres, não destituir o marido de sua posição central de verdade e autoridade para a mulher casada, Beauvoir afirma por um viés crítico:

Sua infância [a da esposa] deixou-lhe a necessidade imperiosa de um guia; quando o marido fracassa no desempenho desse papel, ela volta-se para outro homem (...) Há duas categorias de homens cuja profissão os destina a tornarem-se confidentes e mentores: os padres e os médicos. (2016[1949], p. 352)

A colocação de Beauvoir serve para discorrer sobre a dinâmica entre as personagens de homens e a persona poética em The Awful Rowing Toward God, sendo que outros aspectos de gênero do livro poderiam ser igualmente analisados pela perspectiva da "mística" (BEAUVOIR, 2016[1949], p. 491-500). Assim, a escrita de Anne Sexton contém em si inúmeros pontos pertinentes para a crítica (literária) feminista, para além de seus temas mais explicitamente vinculados 
aos assuntos discutidos pelos feminismos. Retornando à leitura de Adrienne Rich, porém, outro aspecto é trazido à tona a partir da figura pública de Anne Sexton, da relação entre as duas poetas e daquilo que transparece na poesia de Sexton. Todas essas questões podem ser relacionadas com o que Rich chama de veneno quádruplo, que representa as formas pelas quais as mulheres se destroem, inclusive entre si.

A primeira face desse veneno é exemplificada através da relação entre ambas, descrita por Rich como uma hostilidade horizontal (RICH, 1995, p. 122). Atraindo os olhares por sua performance de feminilidade sensual, Sexton causava uma impressão intimidante em Rich, uma vez que esta caracterizava seus esforços enquanto "defeminizing" para sua própria imagem no meio literário (MIDDLEBROOK, 1992, p. 110-111). Assim, ao invés de aliarem-se enquanto companheiras de mesmo ofício, as poetas encaravam-se como rivais, sendo que já enfrentavam dificuldades enquanto mulheres dentro de um ambiente predominantemente dominado por homens. $\mathrm{O}$ segundo aspecto do veneno quádruplo às mulheres seria a falta de atribuição de valor a si próprias, afetando tanto os limites que impõem a outrem quanto as ambições que podem nutrir. A terceira face desse veneno seria a compaixão por agressores/as, atribuindo às mulheres um papel de perdoadoras, o que muitas vezes se volta para atos que não deveriam ser ignorados. Por fim, o quarto aspecto seria o vício pela busca de legitimação masculina, induzido para condicionar o reconhecimento positivo de si através do outro, e nunca por e para si mesma. Conforme argumentado em minha dissertação, todos esses aspectos se encontram visíveis na poética de Anne Sexton, inclusive na obra The Awful Rowing Toward God, na medida em que a persona poética nesse volume é tida como vil, dependente de aprovação social e divina, assim como é alvo de críticas de mulheres ou de seu controle. Logo, discutir os textos dessa poeta é de grande pertinência para localizar as instâncias em que temas debatidos nas reflexões feministas se articulam. Como Adrienne Rich conclama:

I think of Anne Sexton as a sister whose work tells us what we have to fight, in ourselves and in the images patriarchy has held up to us. Her poetry is a guide to the ruins, from which we learn what women have lived and what we must refuse to live any longer. (RICH, 1995, p. 123)

Portanto, resgatar o trabalho de Anne Sexton através da tradução, introduzindo-a na pesquisa acadêmica brasileira contemporânea, é uma forma de relembrar os caminhos pelos quais as vidas e vivências das mulheres foram bloqueadas. Se "Every woman who writes is a survivor" (RICH, 1995, p. 123), conforme Tillie Olsen disse e Adrienne retomou para encerrar o seu ensaio, intuitivamente se pode pensar que essa mesma sobrevivência, em tradução, torna-se a pervivência sugerida por Walter Benjamin (2010, p. 207). Traduzir a poesia de Anne Sexton é multiplicar a sua existência através de tempos e lugares distintos, afirmando que, apesar de sua morte, a poeta se mantém enquanto presença pelo que escreveu. Logo, recriar seu livro de 1975 em 2018, através de 
um projeto de tradução não sexista, talvez seja uma forma de não somente marcar sua sobrevivência, mas assegurar espaço à vida de sua escrita. Ao atentar para os critérios levantados pelos Estudos Feministas de Tradução, é possível evitar convenções sexistas sobre a linguagem e a atividade tradutória que influenciem no conteúdo e forma dos textos de Anne Sexton. Assim, é preciso repassar ainda que brevemente - alguns de seus referenciais para destacar suas categorias de análise e táticas de enfrentamento.

\section{Os Estudos Feministas de Tradução}

Em 2009, um artigo de referência à revisão bibliográfica dos Estudos Feministas de Tradução foi escrito por Olga Castro, “(Re)examinando horizontes en los Estudios Feministas de Traducción: ¿Hacia una Tercera Ola?”, abarcando uma parte representativa de suas problemáticas e vertentes internas até então. Ao tentar situar uma suposta origem desses estudos, é recorrente - e quase inevitável - delimitá-la na escola quebeco-canadense de tradução, responsável, nos anos 90, por teorizar a respeito das experiências subversivas de tradução feminista que tiveram lugar no Canadá nos anos 80. Essa demarcação é problemática, pois desconsidera em termos historiográficos outras formas de reflexão sobre tradução feminista, realizadas em outros lugares, em outros tempos e por outros meios - especialmente as que não foram escritas e não são anglófonas. Porém, os trabalhos quebeco-canadenses têm sido tomados como referenciais, de base e/ou crítica, ainda mais pela repercussão transnacional que tiveram e ainda possuem. De toda forma, pode-se pensar que os Estudos Feministas de Tradução hoje seguem em diálogo com essa geração, representada frequentemente por Luise von Flotow, Sherry Simon, Barbara Godard e Susanne de Lotbinière-Harwood. Luise von Flotow levou adiante essa proposta na Universidade de Ottawa através da virada do século, publicando artigos e organizando volumes (2011, 2017), para além de Translation and Gender: Translating in the 'Era of Feminism' (1997), seu livro que é um dos marcos das produções dessa primeira geração, ao lado do pioneiro Gender in Translation: Cultural Identity and the Politics of Transmission (1996), de Sherry Simon.

O artigo de Olga Castro, traduzido ao português em 2017, mapeia essas produções feministas e reconhece suas propostas dentro de uma tendência maior nos Estudos da Tradução - que também afetou outras disciplinas da linguagem e das ciências sociais -, a chamada virada cultural. Ao se enfocar menos no produto, como nos Estudos Descritivos de Tradução, e observar mais o processo, foi possível visualizar melhor os aspectos ideológicos presentes na tradução. Esses orientam não somente os fluxos de textos traduzidos, mas quem os realiza e para quem, como, porque, para que, entre outras perguntas. Esses questionamentos já eram estudados através da Teoria dos Polissistemas, como pontua Castro (2009), e foram muito desenvolvidos na Tradução Cultural, ainda que esta tomasse a tradução mais como metáfora da relação entre culturas e a circulação de pessoas, e não se concentrasse tanto em suas práticas tradutórias de fato (PYM, 2017). 
Ao evidenciar os elementos ideológicos que interferem nas mediações literárias via tradução, é possível criticá-los e pensar outras formas de traduzir, outros tipos de agentes, motivações, propósitos, fluxos, e assim em diante, em prol de práticas menos excludentes, desiguais e opressoras. As formas de violência epistemológica e simbólica, que são reflexos e que agem retroalimentando as violências sociais, manifestam-se de diversas formas, como através do gênero. Conforme Olga Castro traz em sua reflexão sobre a contribuição da perspectiva crítica feminista à tradução, "os feminismos constataram que o fato de não subscrever de forma consciente uma ideologia particular em tradução implica aderir de forma inconsciente à ideologia dominante (patriarcal)" (2017, p. 221), uma vez que o conceito de normalidade é socialmente construído em consonância com o que é tomado por majoritário e de interesse das elites. Em tradução, isso é perceptível, por exemplo, na predominância de tradução de textos escritos por homens, o que mostra como as barreiras às mulheres nos fluxos literários são duplicadas: primeiro para serem reconhecidas em seus próprios países - devido ao cânone dominado por homens - e, depois, para conseguirem visibilidade nacional forte o suficiente que possibilite seu reconhecimento fora, um dos possíveis motivos de sua tradução.

Os Estudos Feministas de Tradução, portanto, questionam quem possui textos traduzidos ou não, mas apresentam vertentes internas: crítica (analisando traduções para demonstrar se questões de gênero são mantidas, anuladas ou reforçadas de forma estereotipada, assim como o tratamento geral dado ao processo de tradução), histórica (ao resgatar o trabalho de escritoras, tradutoras e a recepção de suas obras), política (na discussão teórica sobre como conceitos feministas podem auxiliar na elaboração de práticas tradutórias) e prática (ao efetivamente articular essas ideias em prol de estratégias para tradutores/as), como é possível reconhecer nas últimas publicações sobre o tema (cf. CASTRO, 2009; BLUME, 2010; CASTRO E ERGUN, 2016; FARAHZAD; FLOTOW, 2017; AKUJÄRVI, ALVSTAD, LINDTNER e LÓPEZ, 2018). É visível um maior enfoque na perspectiva transnacional, contra estudos europeus e norte-americanos voltados apenas sobre si próprios; e minuciosamente contextualizados, articulando questões de raça, classe, sexualidade, religiosidade, geografia, entre outros critérios localizados, abrangendo uma proposta mais interseccional. No entanto, ainda se submetem à hegemonia do inglês para sua transmissão mais ampla - como se discorre no dossiê do Simpósio de Perspectivas Comparadas "Translation, Feminist Scholarship, and the Hegemony of English", no periódico Signs (HAWKESWORTH, 2014) —, porém não sem justificativas embasadas, como Castro e Ergun escrevem na introdução ao livro Feminist Translation Studies (2016).

No que concerne à minha própria pesquisa, esses estudos reafirmaram a escolha da autora com quem estava a trabalhar, Anne Sexton, e auxiliaram-me a organizar critérios para guiar minha tradução e sua reflexão em comentário. Além disso, desfizeram ideias preconcebidas sobre minha prática, contribuindo para uma visão menos ingênua sobre a atividade. Por exemplo, James Underhill (2011) é um pesquisador que colabora com a dissolução de mitos essencialistas 
na tradução de textos de mulheres, demonstrando que tanto mulheres quanto homens, ao traduzirem poemas de Emily Dickinson, atentaram contra a poética da autora. Assim, ao traduzir os poemas de The Awful Rowing Toward God, busquei conciliar os parâmetros de tradução poética (ritmo, som, imagética, aspecto visual) com as questões de gênero, uma vez que estas, dentre os tópicos de discussão feminista, foram as que apareceram efetivamente no processo de traduzir. Portanto, ao invés de hierarquizar critérios, assumindo a supremacia de algum, propus a coexistência de cuidados entre a poesia e a ideologia manifestada através da língua. No caso entre o português brasileiro ${ }^{2}$ e o inglês, ${ }^{3}$ existe um fator determinante para percebê-la em termos formais: a distinção entre sistemas gramaticais de gênero, uma vez que no português brasileiro ele existe e, no inglês, não. Ao traduzir os poemas de Anne Sexton, essa diferença entre sistemas esteve presente de duas formas: 1) ao interferir na marcação de gênero da imagem da Morte, que não é isolada em sua obra, mas está vinculada a uma tradição poética; 2) ao exigir delimitação de gênero gramatical em inúmeras passagens em que ela não era explícita, o que demandou uma reflexão para não incorrer em procedimentos da ideologia dominante. Antes de deter-me nos escritos de Olga Castro sobre esse assunto, que ela tem chamado de traducción no sexista, considero importante explicitar uma elaboração que endossa a perspectiva geral de meu trabalho.

Para além dessas contribuições que se evidenciam pontualmente nas escolhas de tradução, as propostas teóricas de Mona Baker, com uma preocupação política sobre as mediações ideológicas tradutórias - conforme escrito anteriormente —, foram muito importantes para elaborar um projeto de tradução não sexista. Com base na teoria social da comunicação, Baker auxilia os Estudos da Tradução ao tomar dela o conceito de narrativa, para vislumbrar a atividade tradutória enquanto um (re)enquadramento: se as narrativas contadas (por nós e para nós, em mútua constituição) compõem um elemento formador de nossas vivências e crenças, enquadrando nossa realidade, a tradução recontaria essas histórias, deslocando-as de seus contextos (2007, p. 151). Ao sugerir o conceito de (re) enquadramento à tradução, Baker se diferencia de duas grandes tendências nos Estudos da Tradução: 1) de Gideon Toury e Itamar Even-Zohar, ao considerar práticas minoritárias e de resistência, e não somente os grandes padrões sociais de comportamento tradutório conforme estudados pela Teoria dos Polissistemas; 2) de Lawrence Venuti, ao matizar a dicotomia entre estrangeirização (deixando marcas da cultura de partida) e domesticação (trazendo o texto para perto da cultura de chegada) na tradução, pois sugere que ambas estratégias são empregadas dentro de um mesmo texto, dependendo daquilo que estiver em jogo na tradução. Assim, Mona Baker colabora para um entendimento da complexidade das negociações realizadas no processo de tradução, mostrando não somente tendências gerais, mas oferta espaço para práticas contra-hegemônicas e entende que esse processo pode requisitar procedimentos sutilmente intrincados, que não atuam em um binarismo simplista.

A pesquisadora propõe essa abordagem para abarcar os/as agentes reais implicados nas traduções, considerando identidades contextualmente específicas 
em relações dinâmicas, o que inclui tanto as tendências quanto as oposições a elas. Um texto literário, por exemplo, é marcado pelo que seu/sua autor/a escreveu (uma narrativa), que não necessariamente apresenta uma coerência ideológica interna, mas também pela editora que o/a publicou, considerando desde editores/as, revisores/as, preparadores/as de texto e desenvolvedores/as de projeto gráfico (multiplicam-se as narrativas); entre outros/as. Assim, ao traduzir, um outro conjunto de agentes se mobiliza, cada um/a com suas próprias questões ideológicas envolvidas (outras tantas narrativas), portanto, uma grande rede de ideias, em harmonia ou conflito, se articula para gerar o produto final, sendo que cada agente pode possuir distinta carga de poder decisório, o que não exclui atitudes de resistência a ele (2007, p. 152-155). Nesse processo, Baker descreve o enquadramento como uma forma de estruturar as narrativas, dividindo-o em passivo (organização ao discurso que se forma pela interação) e ativo (postura elaborada por um/a agente que conduz um discurso ou se apresenta previamente à interpretação de um) (2007, p. 155-6). Esse enquadramento, pois, está carregado ideologicamente - em sua forma e/ou conteúdo - de tal sorte que compreendêlo faz parte de uma consciência ativista da interpretação de textos e, também, de sua tradução. O (re)enquadramento, por sua vez, seria pensar como essas representações se deslocam no processo de tradução, através do tempo, espaço e culturas distintas, tendo em vista uma determinada ética a ser elegida pelos/ as agentes envolvidos/as (BAKER, 2008). É por esse motivo que, ao propor-me a traduzir os poemas de Anne Sexton por um viés não sexista, realizo um (re) enquadramento do livro The Awful Rowing Toward God, publicado em Boston em 1975 e escrito em 1974, em O Terrível Rumar Rumo a Deus, para Florianópolis em 2018, considerando as questões gramaticais de gênero como representativas à visibilidade às desigualdades sociais de gênero. Ao compreender a pertinência dos escritos de Anne Sexton, e de sua vida, ao debate feminista, firmo essa postura política ao traduzir, consciente das peculiaridades desse processo.

Retornando à tradução não sexista em si, Olga Castro a elabora no capítulo "Traducción no sexista y/en el cambio social: el género como problema de traducción" do livro Translating/Interpreting and Social Activism - Compromiso social y Traducción/Interpretación (2010), editado por Carol Maier e Julie Boérie. Ainda que tenha em vista a tradução independentemente do gênero textual, seu capítulo traz importantes reflexões sobre o aspecto discursivo (o meio pelo qual as representações de gênero social são feitas em textos e recriadas em traduções) e da palavra (a manifestação do gênero gramatical, por exemplo), considerando línguas com distintos sistemas, ao trabalhar com o par castelhano-inglês. Apesar das diferenças entre o português e o castelhano quanto ao gênero gramatical de alguns substantivos, ambas línguas apresentam um sistema em que esse é um fator determinante, ao contrário do inglês: os substantivos referentes a objetos e seres não sexuados não apresentam gênero. Consequentemente, adjetivos e alguns pronomes não sofrem efeito de concordância, muito diferentemente do que ocorre em línguas marcadas. A problemática dessa questão se dá naquilo que Castro toma dos estudos de Friederike Braun, o "Male-As-Norm-Principle", no qual, além de 
haver um comportamento ideologicamente induzido de supor que referentes sem marca de gênero são masculinos, isso está tão impregnado que até se apresenta onde uma revisão perceberia erro ou absurdo. Exemplo disso se encontra no capítulo sobre as teorias desconstrutivistas no livro Teorias Contemporâneas da Tradução, em que o tradutor do inglês para o português se refere às intelectuais Tejaswini Niranjana e Gayatri Spivak como "dois dos mais influentes estudiosos" da área (GENTZLER, 2009[2001], p. 218).

O que isso levanta pode ter sutis ou grandes implicações e, como trata-se de pensar essa proposta para a tradução poética, alguns casos podem ser levantados para exemplificar as dimensões que isso afeta. Na poesia contemporânea brasileira, Luiza Romão joga com esse tema em seu livro Sangria, ao relacionar concordância de gênero não somente como algo textual, mas pungentemente real:

\author{
DIA 3. NÚMERO DE REGISTRO \\ a filho não ter o filiação da pai \\ no certidão de nascimento \\ é hábito antiga \\ agora o mãe exigir direito à aborto \\ é uma crime de vida \\ em alguns casos \\ não só a gramática \\ sofre concordância de gênero \\ (ROMÃO, 2017, p. 25)
}

Ao traduzir este poema para o inglês, não se poderia apelar à mesma inventividade da poeta, pois ela realiza sua crítica ao inverter o gênero gramatical das palavras, traço inexistente na outra língua. Foi por isso que a autora concordou que a tradutora escrevesse uma nota de rodapé, explicitando o que houve no poema em português, pois em inglês só se entenderia o conteúdo da crítica, mas não a forma que dialoga com ela (BARBOZA, 2018, online). Outro exemplo: se, em uma língua com marcação, substantivos apresentam gênero, como em castelhano "la sangre" e em catalão "la sang" (palavras ambas femininas), ou em português "o sangue" (masculina), em outra sem, como o inglês, "the blood", certas nuances do texto são alteradas. Isso é perceptível, por exemplo, na poética da poeta feminista catalã Maria-Mercè Marçal, quando ela escreve o verso "nua com una sang" (MARÇAL, 2017, p. 431). Além da potente conotação imagética que o sangue possui em relação às mulheres em sua escrita (BARBOZA e MARSAL, 2018, p. 143), o adjetivo para nudez contém as mesmas letras que o artigo indefinido no feminino. Poeticamente, essa sonoridade estabelece uma rima assonante com outros versos do poema “T’estimo quan et sé nua com una nena", ritmado em alexandrinos, forma relevante na medida em que Marçal se propunha a escrever dentro das estruturas poéticas tradicionais, inserindo a vivência das mulheres lésbicas numa história que as invisibilizou e excluiu assim como fez Adrienne Rich, uma de suas "mães literárias" (BARBOZA e 
MARSAL, 2018, p. 139). Assim, mesmo que as tradutoras tenham optado por não criar um estranhamento no texto, recriando o verso como "nua como um sangue", através de seus comentários à tradução elas explicitam a carga feminista do poema, outro recurso paratextual como aquele adotado pela tradutora do livro de Luiza Romão. Percebe-se que, mesmo entre duas línguas com sistema gramatical de gênero, as diferenças podem surgir e ter relevância, mas o recurso paratextual das tradutoras funciona como contrapeso.

É por isso que Olga Castro delineia uma metodologia de tradução não sexista com base em três etapas, não necessariamente sequenciais: 1) a leitura crítica; 2) a reescritura ativa; 3 ) a ética de tradução (2010, p. 302). Esta última tem recebido amplo debate nos Estudos da Tradução, que reconhecem não haver consenso sobre qual ética deve ser adotada em traduções (INGHILLERI e MAIER, 2008), mas os Estudos Feministas de Tradução se comprometem com um engajamento feminista contra as opressões manifestadas na linguagem. Para a leitura crítica, por sua vez, ela adota as contribuições de Sara Mills com o chamado "feminismo linguístico de terceira onda", compreendendo as palavras em seus contextos para evitar essencialismos e generalizações. O segundo processo, por sua vez, recebe grande destaque, e Castro nomeia técnicas com base nas reflexões de Anne Pauwels e Edward Said, que não deixam de ecoar em alguma medida aquelas definidas por Luise von Flotow como supplementing, prefacing e footnoting (1991), embora sejam diferentes e envolvam mais tipos. Castro (2010) então descreve cinco formas de pensar uma tradução não sexista: 1) pela compensação (ora neutralizando/generalizando para evitar uma especificidade sexista, ora especificando/feminizando de forma inclusiva, como "leitor/a", contra o masculino como universal para a espécie humana); 2) pelo transtorno linguístico (em intervenções gráficas e/ou neologismos, para visibilizar mulheres ao criar palavras distintas para o feminino e o masculino); 3) pela correção do texto (quando o texto de partida usa uma palavra ou expressão sexista, e na tradução se desfaz essa carga); 4) pela escolha em contraponto (quando é preciso marcar o gênero e não há forma de fazê-lo inclusivamente, então se deve escolher com o cuidado de não reproduzir estereótipos); 5) pelo uso de metatextos (todos os escritos incluídos junto ao texto, mas não traduzidos dele, em que tradutores/ as, revisores/as e editores/as podem comentar sobre o que foi feito na tradução, justificando escolhas, ou até denunciando questões do texto de partida). Esta última técnica, conforme visto nos exemplos citados, foi importante nas traduções dos poemas de Maria-Mercè Marçal e Luiza Romão, para justificar escolhas em contraponto (no caso da primeira) e a impossibilidade de compensar o texto na tradução (na segunda).

É com base nessa estratégia de tradução não sexista, firmando minha postura enquanto agente de (re)enquadramento, que traduzi os poemas de Anne Sexton no livro The Awful Rowing Toward God de 1975, poeta valorizada pela crítica feminista. Atenta aos critérios de tradução poética, como ritmo, som, imagética e aspecto visual, busquei negociá-los com meu posicionamento de tradutora feminista. 


\title{
Uma tradução não sexista do livro The Awful Rowing Toward God
}

Construída pelas reflexões de Mona Baker e as estratégias de Olga Castro, essa abordagem esteve presente de várias formas na tradução do livro The Awful Rowing Toward God, de Anne Sexton. Dos 39 poemas, tomarei dez para exemplificar a multiplicidade dessas negociações, mas um caso para além desses se destaca por envolver questões mais complexas, envolvendo o diálogo que a poeta estabeleceu com outras escritoras através da tradição. Portanto, antes de passar para os outros poemas, começarei discutindo a figura da Morte no poema "After Auschwitz". O poema, talvez um dos mais carregados de raiva do volume, enfatiza o pessimismo da persona poética e seu desejo de condenação dos homens:

\author{
Anger, \\ as black as a hook, \\ overtakes me. \\ Each day, \\ each Nazi \\ took, at 8:00 A.M., a baby \\ and sautéed him for breakfast \\ in his frying pan. \\ And death looks on with a casual eye \\ and picks at the dirt under his fingernail. \\ Man is evil, \\ I say aloud. \\ Man is a flower \\ that should be burnt, \\ I say aloud. \\ Man \\ is a bird full of mud, \\ I say aloud. \\ And death looks on with a casual eye \\ and scratches his anus. \\ Man with his small pink toes, \\ with his miraculous fingers \\ is not a temple \\ but an outhouse, \\ I say aloud. \\ Let man never again raise his teacup. \\ Let man never again write a book. \\ Let man never again put on his shoe. \\ Let man never again raise his eyes, \\ on a soft July night. \\ Never. Never. Never. Never. Never. \\ I say these things aloud. \\ I beg the Lord not to hear. \\ (SEXTON, 1975, p. 26-27)
}


Apesar dos critérios de tradução poética pertinentes ao poema inteiro, entre suas aliterações e assonâncias, contando com paralelismos sintáticos e de uma heterogeneidade rítmica, desejo destacar a segunda e quarta estrofes, nas quais a Morte aparece. Apesar de não levar letra maiúscula para personificar uma entidade, seus gestos no poema denotam que ela tem um corpo, possivelmente antropomórfico. Se o substantivo em inglês não possui gênero, Sexton o marca como masculino ao escolher "his" para referir-se às unhas da mão e ao ânus da morte, ao invés de utilizar o pronome neutro "its". Esse tipo de particularização, que não é obrigatória, sugere uma volição, motivada seja por um fator individual seja por uma conexão com algo para além da poeta. Neste caso, pode-se vinculá-la à literatura de Emily Dickinson, como foi descoberto através da discussão de James Underhill.

Ao comentar sobre Dickinson, o pesquisador expõe como as traduções ao francês de seus poemas ignoraram a marcação de gênero: "with regard to gender, no (or little) attempt is made to render gendered personification, which is very present in Dickinson's poetic practice. Where Death is masculine in her poetry, it becomes feminine in the translations (la mort)" (UNDERHILL, 2011, p. 218). Se a poeta do século XIX escreve a morte no masculino, não é inapropriado supor que Sexton o fez por lê-la, uma vez que Emily Dickinson foi um exemplo para as gerações posteriores, em especial para os/as chamados/as poetas confessionais, segundo Rachel Wetzsteon (2003). Sobre a morte em si, a comentadora afirma com ainda mais especificidade: "several poets, like Dickinson before them, make death a character: Anne Sexton titled one of her poems 'For Mr. Death Who Stands with His Door Open', and Sylvia Plath's 'Death \& Co.' personifies not one but two Deaths" (2003, p. xxxii). No poema de Sexton mencionado, a morte está no masculino, assim como em todos os outros casos, de tal forma que apagar essa marcação de gênero, ao traduzir o poema para o português brasileiro, seria ignorar uma filiação literária.

Para conseguir escolher uma figura que se escrevesse no masculino, a solução encontrada foi a da morte enquanto o Ceifador, uma de suas representações "ocidentais" de grande conhecimento popular. Essa figura é compartilhada pelo imaginário anglófono como The Grim Reaper, ou apenas The Reaper: "O Grim Reaper, mais conhecido como O Ceifador, no Brasil, é alegoria comum da morte no imaginário coletivo ocidental, representado por um esqueleto vestido de preto que carrega uma foice para desprender a alma de corpo" (CHEVALIER; GHEERBRANT, 1998, p. 622 apud FIORI, 2017, p. 132). Ainda que o livro seja carregado por uma imagética tanto católica quanto protestante e a figura d'O Ceifador não seja a mais apropriada a esse contexto, ela ainda se situa no "imaginário coletivo ocidental" no qual Anne Sexton teve sua formação. Portanto, é possível considerar esta como uma opção válida em prol dos debates de gênero pertinentes à sua vinculação literária. Assim, as passagens foram recriadas da seguinte forma: 
E o ceifador só observa com um olhar casual e tira a sujeira embaixo de sua unha da mão. (...)

E o ceifador só observa com um olhar casual e coça seu ânus.

Adiante, sigo com outros exemplos pontuais sobre escolhas que demandaram pensar a partir da tradução não sexista, considerando dez poemas entre os 39 . Dentro da proposta poética de Anne Sexton, ela não faz uso de transtornos linguísticos, de tal sorte que desconsiderei o recurso a essa técnica na tradução. Também não trabalhei com a correção do texto, mas evitei que aquilo que não havia sido marcado pela autora se tornasse definido, de forma sexista, pela diferença entre os sistemas gramaticais entre as línguas. A tática que mais se fez presente foi a de compensação, em suas duas vertentes, seguida pela escolha em contraponto, e este artigo, assim como os comentários de minha dissertação, se constituem como um amplo conjunto de metatextos.

Dentre as compensações, quatro foram na direção da generalização para serem mais inclusivas. A primeira ocorreu no poema "The Poet of Ignorance" (SEXTON, 1975, p. 28-29), entre os seguintes versos:

Perhaps God is only a deep voice heard by the deaf

Para evitar uma leitura sexista do referente "deaf", propus a seguinte reescrita na forma de abstração, que ecoou a palavra em inglês, pois a vogal tônica de [ê] de "surdez" ressoa mais ao [é] de "deaf" do que o [u] de "surdos" (na tradução sexista que usasse o masculino como genérico):

Talvez Deus seja só uma profunda voz escutada na surdez

Seguindo à frente, o poema "Is It True?" (1975, p. 48-57) apresenta a passagem:

True, I have friends,

a few,

each one is a soul in two bodies.

Each one is a man or a woman.

Como o próprio texto explicita que "friends" se aplica tanto a mulheres quanto a homens, seria ainda mais sexista o uso do masculino genérico "amigos", que levaria outros termos a estarem no masculino também ("few", "each one"). Portanto, traduzi esses versos sem marcar o gênero que invisibilizasse a presença das mulheres, e apenas se fez a concordância com o gênero gramatical do substantivo: 
É verdade que tenho amizades, algumas, cada uma é uma alma em dois corpos.

Cada uma é um homem ou uma mulher.

A terceira situação envolve tanto o título do poema quanto um de seus versos, “The God-Monger” (1975, p. 62-63). Como a referência é à própria persona poética, traduzi o título como "A Negociante de Deus". O verso em questão foi:

past the stones as solemn as preachers,

Aqui, ainda que o estereótipo do/a agente que realiza pregação religiosa seja a imagem de um homem, incorrer nesse tipo de generalização sem tentar encontrar outro caminho para evitá-la é seguir a ideologia dominante. Logo, optei por trocar o substantivo marcado com uma ação por uma expressão em que o verbo caracteriza as pessoas em questão:

através de rochas tão solenes quanto quem prega,

O último caso de generalização/neutralização, dentre esses exemplos, ocorreu ao longo de "The Big Heart" (1975, p. 69-70). No poema, os pronomes pessoais são usados para sujeitos ("they") e objetos ("them") que se referem tanto a mulheres quanto a homens, pessoas queridas para a persona poética que fala sobre elas e eles. No caso dos sujeitos na terceira pessoa, foi possível transformálos em sujeitos ocultos, sem que fosse preciso escolher um pronome que marcasse gênero. Nas ocorrências do pronome pessoal na situação de objeto, a chave foi encontrada dentro do próprio texto: Sexton se refere a elas e eles como "people", o que, ao traduzir como "pessoas", permitiu-me realizar a concordância com essa palavra e deixar todas as referências no feminino ("elas" e "nelas").

Uma vez que partiam de situações um pouco mais evidentes, os casos de especificação exigiram menos desdobramentos, mas foi preciso cuidado. O primeiro caso, no poema "The Civil War" (SEXTON, 1975, p. 3-4), apresenta dois momentos de marcação: quando a persona poética caracteriza uma parte de si como "the beggar" e depois qualifica sua atitude em "with the patience of a chess player". Fazendo concordância com o gênero da persona poética, reconhecido como feminino, as traduções foram "a mendiga" e "com a paciência de uma enxadrista". Uma situação complicada, no entanto, deu-se em "The Play" (SEXTON, 1975, p. 38-39):

I am the only actor.

It is difficult for one woman to act out a whole play.

Apesar de situar-se enquanto mulher, a persona poética se define como "actor" e não "actress". Existe um debate jornalístico sobre o uso de "actor", tanto 
para homens quanto para mulheres, na atualidade (cf. GUARDIAN, 2018), mas o colunista Stephen Pritchard afirma: "Being obliged to describe someone as a 'female actor' suggests that we still consider the term actor to be fundamentally male, so why not keep the unambiguous 'actress'?" (PRITCHARD, 2011, online). A palavra "actor" para atrizes se tornou de uso generalizado nos últimos anos, mas ainda existem as premiações que incluem a palavra "actress", como o Oscar, Cannes, o Festival de Berlim, entre outros. Isso, no entanto, é recente, o que não seria válido para a época de Sexton. Logo, se no texto de 1975 escreveu "actor", na tradução mantive "ator" para deixar visível que ela deliberou por seguir a ideologia dominante em sua postura linguística, e utilizo este espaço metatextual para que isso seja exposto.

Em "Fire Thief" (1975, p. 66-68), outro tipo de solução foi buscado, com relação ao trecho:

They did not listen forever

for they burned Joan

and many, and many,

burned at the stake,

Como os/as hereges aos/às quais a persona poética faz referência neste poema poderiam ser mulheres e homens, a escolha por manter as duas ocorrências de "many" no feminino induziria à leitura de que somente mulheres eram perseguidas. Portanto, optei por uma especificação alternada, assim como o sujeito indeterminado para o primeiro e segundo verso:

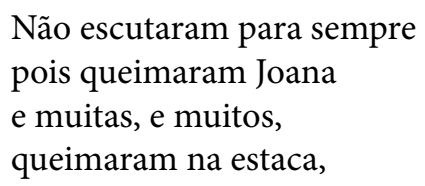

Em "Doctors" (SEXTON, 1975, p. 74-75), o recurso do sujeito oculto foi útil, porém não o suficiente, ainda que tenha se conciliado com as exigências rítmicas dos versos, pois o título e as várias menções a "doctors" dentro do poema demandavam especificar o gênero. Para realizar uma escolha em contraponto consciente, contra preconceitos relacionados às ocupações profissionais, obtive informações a respeito da classe médica nos Estados Unidos da época em que o texto foi escrito: "by 1974, $22.4 \%$ of medical school entrants were women, and by $199017 \%$ of the physician workforce was comprised of women" (STAFF CARE, 2015, p. 3). Logo, se, mesmo no começo da década de noventa, menos de um quinto das/os profissionais da medicina era de mulheres, não é descabido traduzir "doctors", no poema de Sexton, por "doutores", uma vez que é um fato e não uma pressuposição sexista - ainda que se fundamente em uma desigualdade social provocada pela dominação sexista. Outros poemas que incluíam referências a profissões da saúde, como em “The Fallen Angels” (SEXTON, 1975, p. 22-23) 
e "The Poet of Ignorance"(1975, p. 28-29), também levaram substantivos no masculino por conta dessa investigação.

Por fim, apresento um poema em que não pude encontrar satisfatoriamente uma via de tradução não sexista: o "The Saints Come Marching In" (1975, p. 79-82), cujo título foi mantido em inglês na tradução por ser a variação do nome do hino gospel "When the Saints Go Marching In". Neste texto, a persona poética realiza uma breve hagiografia poética de santos e santas, com inúmeras palavras referentes a eles/as coletivamente, que não poderiam ser suprimidas nem substituídas de forma inclusiva. Os primeiros versos, de pronto, já pedem por uma marcação e mostram como outras palavras demandam concordância a partir do que for definido:

The Saints come, as human as a mouth,

Não se pode suprimir o sujeito da frase, nem o substituir por uma abstração generalizante, pois «santidade» é antes o estado do que o conjunto de santos e santas. Com relutância por não poder recorrer à proposta não sexista, traduzi a passagem como:

Os Santos voltam, humanos como bocas,

Apesar de discordar do uso do masculino genérico, nesse caso tive que recorrer a ele para não entrar em conflito com o que a própria Sexton fazia em seus textos, assim como com os critérios de tradução poética. Se ela fosse uma autora declaradamente feminista, ou seu texto se propusesse a incorporar em sua forma essa postura, ou se minha proposta de tradução fosse de correção do texto, seria possível pensar em outros caminhos, mas não é esse o caso. Acredito, portanto, ter feito o máximo em prol da tradução não sexista ao recriar os poemas de uma autora valorizada pela crítica literária feminista, trabalhando com os Estudos Feministas de Tradução no contexto brasileiro.

\section{Conclusões}

Ao traduzir o livro The Awful Rowing Toward God, de 1975, escrito por Anne Sexton, como O Terrível Remar Rumo a Deus, em 2018, inúmeras perspectivas se cruzaram em minha prática e no pensamento que a antecedeu, naquele que se fez durante ela e o que se formou após. Pode-se dizer que esse processo não acabou, pois ainda que tenha defendido minha dissertação comentada dessa tradução em julho de 2018, neste artigo já apresentei uma versão diferente de um dos versos desde aquela época. A tradução se abre, em si mesma, e para outras que virão a partir do mesmo texto sobre o qual ela se debruçou. Minhas premissas, no entanto, se mantiveram: a necessidade de conciliar os critérios de 
tradução poética com aqueles da tradução não sexista. É por essa razão que hoje, no doutorado, desenvolvo minha tese "Por uma tradução literária não sexista", levando a discussão para a literatura além da poesia.

Neste artigo, procurei situar como a poesia de Anne Sexton foi valorizada pela crítica literária feminista, partindo das observações de Adrienne Rich, para articular sua tradução com uma abordagem ainda mais atenta aos aspectos de gênero. Foi possível localizar os tópicos comentados por ela dentro do próprio The Awful Rowing Toward God, justificando a pertinência desse volume aos debates feministas. Porém, se o conteúdo escrito por Anne Sexton é relevante nesse sentido, sabe-se que ela não se declarava feminista, nem tinha essa preocupação específica na forma como trabalhava seus poemas. Essa compreensão é necessária para medir o quanto a tradução deles é permeável às estratégias feministas, o que busquei demonstrar através dos exemplos de caso - em alguns deles com eficácia, em outros reconhecendo limitações difíceis de contornar. Para fundamentar essa prática, descrevi quais referenciais dos Estudos Feministas de Tradução colaboraram ativamente para tal, como os de Olga Castro e Mona Baker, sucintamente contextualizando esse campo de estudos, ainda tão novo.

Ainda que brevemente, procurei expor a pertinência dos trabalhos realizados pelos Estudos Feministas de Tradução à tradução em si, considerando uma agente real, situada em um contexto distinto daquele em que o livro em inglês foi escrito. Contribuindo para uma prática contra-hegemônica, tais discussões e atividades se configuram como políticas de tradução de resistência, fundamentadas em reflexões teóricas densamente entrelaçadas. Não perdem de vista, no entanto, as possibilidades e limitações de cada pessoa envolvida na tradução, e reconheço que tais posicionamentos enfrentam reações conservadoras de segmentos sociais (como editoras, revisores/as, público leitor, entre outros/as). Porém, argumento que é preciso resistir e incentivar mediações, como a tradução, que não reforcem aspectos opressores manifestados na linguagem.

Agradecimentos: Ao meu orientador de mestrado entre 2016 e 2018, Gilles Jean Abes, às professoras Olga Castro, Luise von Flotow e à minha atual orientadora de doutorado, Meritxell Hernando Marsal.

\section{Notes}

1. Artigo derivado de pesquisa de mestrado orientada pelo professor Gilles Jean Abes (PGET-UFSC), já defendida.

2. Especifico "português brasileiro" somente para localizar minha prática no Brasil, mas o debate sobre o que significa referir-se a ele, tendo em vista os inúmeros usos e expressões da língua em território brasileiro e fora dele, extrapola os limites deste artigo. No que se refere ao gênero gramatical, porém, pode-se tecer comentários mais gerais, uma vez que este não se altera com tanta frequência entre falantes do português brasileiro.

3. Seguindo ao comentário da nota anterior, também é problemático falar na existência de um "inglês" genérico, desconsiderando suas diversas variantes 
ao redor do mundo. Porém, no que tange o gênero gramatical, exceto por usos específicos, é uma língua que não o apresenta independentemente de suas variações, exceto em pronomes e em alguns substantivos.

Referências bibliográficas e trabalhos mencionados

AKUJÄRVI, J.; ALVSTAD, C.; LINDTNER, S. S.; LÓPEZ, I. H. (Org.). Gender and Translation: Understanding Agents in Transnational Reception. Québec: Éditions québécoises de l'œuvre, 2018.

BAKER, M. Reframing Conflict in Translation. Social Semiotics, 17:2, 151-169, 2007.

BAKER, M. Ethics of Renarration. Cultus, vol. 1, no. 1, 10-33, 2008.

BARBOZA, B. R. G. We are all earthworms: tradução comentada do poema 'The wall' de Anne Sexton. eLyra, no. 9, 06/2017, p. 335-352.

BARBOZA, B. R. G. From Sangria to Bloodletting: translating Brazilian feminisms. In: Translating Women, 2018. Disponível em:<http://blogs.exeter.ac.uk/ translatingwomen/2018/10/24/translating-brazilian-feminisms/>. Acesso em 11 de novembro de 2018.

BARBOZA, B. R. G.; MARSAL, M. H. Falar em língua abolida: a tradução de Desglaç, de Maria-Mercè Marçal, para o português. In: Criação \& Crítica, no. 20, 2018, p. 137-151.

BASSI, S. Displacing LGBT: Global Englishes, Activism and Translated Sexualities. In: CASTRO, Olga; ERGUN, Emek. Feminist Translation Studies: Local and Transnational Perspectives. Nova Iorque/Londres: Routledge, 2016, p. 235-248.

BEAUVOIR, S. de. O Segundo Sexo, vol. 2. Trad. Sérgio Milliet. Rio de Janeiro: Nove Fronteira, 2016[1949], 3a. edição.

BENJAMIN, W. A Tarefa do Tradutor. Trad. Susana KampffLages. In:HEIDERMANN, W. (Org.). Clássicos da Teoria da Tradução, 2a. edição, revisada e ampliada. Florianópolis: UFSC/Núcleo de Pesquisas em Literatura e Tradução, 2010, p. 202-233.

BLUME, R. F. Teoria e prática tradutória numa perspectiva de gênero. In: Fragmentos, número 39, jul - dez/ 2010, p. 121-130.

BOOTH, M. Three's a Crowd: The Translator-Author-Publisher and the Engineering of Girls of Riyadh for an Anglophone Readership. In: FARAHZAD, F.; FLOTOW, L. v. (Org.). Translating Women: Different Voices and New Horizons. Nova Iorque/ Londres: Routledge, 2017, p. 105-119.

CASTRO, O. (Re)examinando horizontes en los Estudios Feministas de Traducción: ¿hacia una tercera ola? MonTI: Monografías de Traducción e Interpretacción, Vol. 1, 2009, p. 59-86.

CASTRO, O. (Re)examinando horizontes nos Estudos Feministas de tradução: em direção a uma terceira onda? Trad. de Beatriz Regina Guimarães Barboza. TradTerm, v. 29, Julho/2017, p. 216-250.

CASTRO, O. Traducción no sexista y/en el cambio social: el género como problema de traducción. In: BOÉRIE, J. B.; MAIER, C. (Org.). Translating/Interpreting and Social Activism-Compromiso social y Traducción/Interpretación [Bilingual edition]. Manchester, St. Jerome Publishing \& Granada, Ecos, 2010, 106-121.

CASTRO, O.; ERGUN, E. Feminist Translation Studies: Local and Transnational Perspectives. Nova Iorque/Londres: Routledge, 2016.

FIORI, F. M. The Raven, de Edgar Allan Poe: o poema, suas traduções e recriações. Pontos de Interrogação, v. 7, n. 1, jan.-jun., p. 123-142, 2017. 
GENTZLER, E. Teorias Contemporâneas da Tradução. Traduzido por Marcos Malvezzi. São Paulo: Madras, 2009[2001].

GILL, J. Anne Sexton's confessional poetics. Gainesville: The University Press of Florida, 2007.

GREENE, R.; CUSHMAN, S.; CAVANAGH, C.; RAMAZANI, J.; ROUZER, P.; FEINSOD, H.; MARNO, D.; SLESSAREV, A. The Princeton encyclopedia of poetry and poetics. New Jersey: Princeton University Press, 2012 [4a. edição].

GUARDIAN. Guardian and Observer style guide: A. Disponível em:< https://www. theguardian.com/guardian-observer-style-guide-a $>$. Acesso em 9 de maio de 2018.

FARAHZAD, F.; FLOTOW, L. v. (Org.). Translating Women: Different Voices and New Horizons. Nova Iorque/Londres: Routledge, 2017.

FLOTOW, L. v. Feminist Translation: Contexts, Practices and Theories. TTR: traduction, terminologie, rédaction, v. 4, n. 2, 20 sem., 1991, p. 69-84.

FLOTOW, L. v. Translation and Gender: Translating in the 'Era of Feminism'. Manchester: St. Jerome Publishing, 1997.

FLOTOW, L. v. (Org.). Translating Women. University of Ottawa Press: Ottawa, 2011.

HAWKESWORTH, M. (Edit.). Signs: Journal of Women in Culture and Society. Chicago: University of Chicago Press, 2014.

INGHILlERI, M.; MAIER, C. Ethics. In: BAKER, M. (Org.). Encyclopedia of Translation Studies. Nova Iorque/Londres: Routledge, 2008 (2a. edição), p. 100103.

MARÇAL, M. Llengua abolida - Poesia Completa 1973-1998. Barcelona: Edicions 62, 2017.

MIDDLEBROOK, D. W. Anne Sexton: A Biography. Nova York, Vintage Books, Random House, 1992.

MORTON, R. The Awful Rowing Toward God. In: Anne Sexton's Poetry of Redemption: The Chronology of a Pilgrimage. New York: Edwin Mellen Press, 1989, p. 114129.

NICHOLS, K. The Hungry Beast Rowing Toward God: Anne Sexton's Later Religious Poetry. In: GEORGE, D. H. (Org.). Sexton: selected criticism. Illinois: University of Illinois, 1988, p. 165-170.

POLLIT, K. The Death is Not the Life. In: The New York Times, 18 de agosto de 1991. Disponível em: <http://www.nytimes.com/1991/08/18/books/the-death-is-notthe-life.html?pagewanted=all $>$. Acesso em 24 de dez. 2017 .

PRITCHARD, S. The readers' editor on... Actor or actress? In: GUARDIAN, 2011. Disponível em: <https://www.theguardian.com/theobserver/2011/sep/25/ readers-editor-actor-or-actress $>$. Acesso em 9 de maio de 2018.

PYM, A. Explorando Teorias da Tradução. Trad. Rodrigo Borges de Faveri, Claudia Borges de Faveri e Juliana Steil. São Paulo: Perspectiva, 2017.

RICH, A. On Lies, Secrets and Silences: Selected Prose 1966-1978. New York: W. W. Norton \& Company, 1995.

ROMÃO, L. Sangria. São Paulo: Edição do Autor, Selo do Burro, 2017.

SANTAEMILIA, J. A Corpus-Based Analysis of Terminology in Gender and Translation Research - The Case of Feminist Translation. In: CASTRO, O.; ERGUN, E. Feminist Translation Studies. Nova Iorque e Abingdon, Reino Unido: Routledge, 2017, p. 15-28. 
SEXTON, A. The Awful Rowing Toward God. Boston: Houghton Mifflin Company, 1975.

SCHURR, W. H. Mysticism and Suicide: Anne Sexton's Last Poetry. In: GEORGE, D. H. (Org.). Sexton: selected criticism. Illinois: University of Illinois, 1988, p. 171-193.

SHREAD, C. On Becoming in Translation: Articulating Feminisms in the Translation of Marie Vieux-Chauvet's Les Rapaces. In: FLOTOW, L. v. (Org.). Translating Women. Ottawa: University of Ottawa Press, 2011, p. 283-304.

SIMON, S. Gender in Translation: Cultural Identity and the Politics of Transmission. Nova Iorque/Londres: Routledge, 1996.

STAFF CARE. Women in Medicine: A Review of Changing Physician Demographics, Female Physicians by Specialty, State and Related Data (2015). Disponível em: $<$ https://www.amnhealthcare.com/uploadedFiles/MainSite/Content/Staffing Recruitment/Staffcare-WP-Women\%20in\%20Med.pdf $>$. Acesso em 21 de setembro de 2017.

TRANSLATION \& MINORITY. Beatriz Regina Guimarães Barboza - Translating Anne Sexton to Brazilian Portuguese: regarding questions of gender. Disponível em:<https://translationandminority.wordpress.com/2017/09/25/tm2-beatrizregina-guimaraes-barboza/>. Acesso em 18 de outubro de 2018.

UNDERHILL, J. W. Echoes of Emily Dickinson: male and female French translators listening to the poet. Trad. por Luise von Flotow. In: FLOTOW, L. v. (Org.). Translating Women. University of Ottawa Press: Ottawa, 2011, p. 203-238.

WETZSTEON, R. Introduction. In: DICKINSON, E. The Collected Poems of Emily Dickinson. New York: Barnes and Noble Classics, 2003, p. xiii-xxxv. 